\title{
PEMIKIRAN TAJDID SYAIKH MUHAMMAD BIN ABDUL WAHHAB DALAM KITAB $A L$-USHUL ATS-TSALATSAH
}

\author{
Finsa Adhi Pratama \\ Institut Agama Islam Negeri (IAIN) Kendari \\ finsaadhipratama@iainkendari.ac.id \\ Ira Trisnawati \\ Institut Agama Islam Negeri (IAIN) Kendari \\ iratrisnawati@iainkendari.ac.id
}

\begin{abstract}
Abstrak
Kondisi sosial keagamaan masyarakat Islam yang terpuruk serta merajalelanya kebodohan sangat berdampak pada pergeseran nilai-nilai agama yang murni. Munculnya berbagai macam kesyirikan, sihir, bid'ah, tahayul, khurafat dan maksiat membuat kaum muslimin semakin jatuh dalam kegelapan ilmu. Realita seperti inilah yang menjadi motivasi Syaikh Muhammad bin Abdul Wahhab mencetuskan pemikiran tajdid (pembaharuan) dalam Islam. Tulisan memfokuskan pada pemikiran tajdid Syaikh Muhammad bin Abdul Wahhab dalam Kitab Al-Ushul Ats-Tsalatsah. Penulis menggunakan metode deskriptif dengan studi penelitian kepustakaan dengan cara mengkaji serta menelaah berbagai data yang berhubungan dengan tajdid Syaikh Muhammad bin Abdul Wahhab. Kesimpulan yang diperolah dari tulisan ini adalah bahwa pemikiran tajdid Syaikh Muhammad bin Abdul Wahhab adalah Ruju' ila alKitab wa As-Sunnah (kembali kepada Alquran dan As-Sunnah), yakni menjadikan Alquran dan As-Sunnah sebagai landasan dasar dakwahnya dengan menghilangkan segala keyakinan dan ibadah yang tidak sesuai dengan tuntunan Nabi Muhammad Sallallahu 'Alaihi Wasallam. Ia adalah seorang ulama Ahlussunnah bermazhab fikih Imam Ahmad bin Hambal. Pemikiran tajdid yang dilakukan Syaikh Muhammad bin Abdul Wahhab bukan hanya berdampak di masyarakat Islam di wilayah Saudi Arabia saja, namun pengaruhnya hampir menjamah ke seluruh negeri-negeri Islam.
\end{abstract}

Kata Kunci: Tajdid; Syaikh Muhammad; Al-Ushul Ats-Tsalatsah

\begin{abstract}
The social and religious condition of the ummah that has been slumped have eroded the authentic values of religious teachings. The emergence of syirik (polytheists), sihr (black magic), bid'ah (religious innovation), tahayul and khurafat (superstition), and maksiat (sins) are evidence that ummah is in the darkness of religious knowledge. Those evidence that motivated and inspired Syaikh Muhammad Abdul Wahhab to evoke the thought of tajdid (purification). The research focus on the thought of tajdid of Syaikh Muhammad bin Abdul Wahab in his book entitled "Kitab Al-Ushul Ats-Tsalasah". The researcher uses descriptive method and library research to study and analyze the data that have relation to Syaikh Muhammad bin Abdul Wahhab's tajdid. The conclusion of the research is that the underlying principle of Syaikh Muhammad bin Abdul Wahhab thought is Ruju' ila al Kitab wa al-Sunnah (back to the Quran and Sunnah) in which he positioned the Quran as the main principle in the thought. He also struggled to eliminate the religious practices that were not suitable with the prophet Muhammad Sallallahu 'Alahi Wasallam. He is the Muslim scholar that followed Ahlusunnah and Ahmad bin Hambal's fiqh. The spirit of renewal that implemented by Syaikh Muhammad bin Abdul Wahhab has a significant effect not only among Muslims in Saudi Arabia but also in muslim countries in the world.
\end{abstract}

Keywords: Tajdid; Syaikh Muhammad; Al-Ushul Ats-Tsalatsah 


\section{Pendahuluan}

Syaikh Muhammad bin Abdul Wahhab yang selanjutnya disebut sebagai Ibnu Abdul Wahhab merupakan nama yang cukup masyhur di kalangan kaum muslimin umumnya khususnya di Saudi Arabia, karena pemikirannya sangat identik dengan Kerajaan Saudi Arabia bahkan menjadi ideologi resmi kerajaan. Ibnu Abdul Wahhab dikenal sebagai salah satu tokoh tajdid (pembaruan) dalam Islam.

Wahhabi adalah nama yang kerap ditujukan kepada para murid Ibnu Abdul Wahhab dan siapapun yang meneruskan pemikirannya. Namun di sisi lain, nama yang kerap digunakan oleh kalangan pengikut Ibnu Abdul Wahha adalah Ahlussunnah, Salafiyyah, atau paling jauh Salafi (Salafiyun) (Waskito, 2011), bahkan ada beberapa kelompok pendukung dakwahnya lebih suka mengenakan istilah umum seperti Islam atau ummat dengan tanpa menyandarkan kepada golongan tertentu.

Pemikiran tajdid Ibnu Abdul Wahhab adalah mengajak kaum muslimin untuk memurnikan ibadah hanya kepada Allah Subhanahu wa Ta'la, menentang keyakinan dan praktek syirik dan khurafat seperti ziarah ke tempat-tempat keramat, meminta perantara kepada yang telah wafat (yang dianggap wali) untuk berhubungan dengan Allah, meminta syafaat kepada ulama, dan sejenisnya serta ancaman bagi yang beribadah kepada selain Allah suhanahu wata'ala (Oliver, 2012).

Pemikiran tajdid Ibnu Abdul Wahhab semakin kuat tatkala bertemu dengan Amir Muhammad bin Su'ud (pemimpin kota Dir'iyah) dan bersepakat untuk bersama mendakwahkan tauhid berdasarkan pemahaman para salafus sholih. (Gunawan, 2013, p. 23). Kerjasama inilah yang kemudian menjadi cikal bakal berdirinya Kerajaan Saudi Arabia.

Menurut Iqbal Gunawan (2013, p. 24) pemikiran Ibnu Abdul Wahhab setelah berkembang di Saudi Arabai mempunyai pengaruh yang sangat kuat di Jazirah Arab yang kemudian menyebar ke berbagai negeri Islam lainnya, termasuk di Indonesia. Oleh karenanya ia kerap disebut sebagai mujaddid (pembaharu) abad XII hijriyah.

Merujuk pada keterangan di atas mengkaji pemikiran tajdid Ibnu Abdul Wahhab dianggap penting dilakukan dengan pertimbangan bahwa masih terdapat kesalahfahaman di kalangan kaum muslimin tentang pemikiran tajdid Syaikh Muhammad bin Abdul Wahhab serta adanya pro-kontra perihal penerapan pemikiran tajdid Ibnu Abdul Wahhab di lingkungan masyarakat muslim. Salah satu contoh dari kesalahfahaman yang terjadi adalah perkara bid'ah yang dianggap mencakup semua 
aspek kehidupan manusia, padahal menurut Syaikh Muhammad bin Abdul Wahhab dalam Al-Ushul Ats-Tsalatsah perkara bi'dah yang dimaksud hanyalah pada ranah ritual ibadah dan tidak mencakup pada ranah fasilitas ibadah.

Penelitian ini diharapkan bisa menjadi solusi titik temu di antara perbedaan persepsi dalam upaya menjaga kehormatan dan hubungan baik di kalangan ulama-ulama ahlus sunnah wal jama'ah khususnya dan kaum muslimin sekalian pada umumnya.

Kajian literatur terdahulu tentang Ibnu Abdul Wahhab pernah diulas oleh Syaikh Ja'far Subhani dengan judul Syaikh Muhammad bin Abdul Wahhab dan Ajarannya (Jakarta : Penerbit Citra, 2007). Buku tersebut menjelaskan tentang perjalanan hidup, aqidah dan gerakan dakwah Ibnu Abdul Wahhab. Ulasan dalam buku tersebut sangat umum dan mencakup semua aspek yang memiliki kaitan dengan Ibnu Abdul Wahhab, namun tidak dibahas detail kitab Al-Ushul Ats-Tsalatsah. Sedangkan pada penelitian ini penulis fokus mengkaji pemikiran tajdid Ibnu Abdul Wahhab dalam Kitab Al-Ushul Ats-Tsalatsah pun pun tidak semua pembahasan akan dikaji, hanya tema-tema yang berkaitan langsung dengan tajdid (pembaharuan).

Penulis menggunakan metode penelitian kepustakaan analisis interpretatif, penulis berusaha untuk menyaring dan meneliti serta mengutip berbagai data, menganalisisnya dan kemudian memberikan interpretasi guna mendapatkan sebuah kesimpulan. Sumber primer yagng digunakan adalah kitab Al-Ushul Ats-Tsalatsah serta sumber penunjang seperti Syarah Al-Ushul Ats-Tsalatsah, Kitabut Tauhid, serta sumber penunjang lainnya yang masih memiliki keterkaitan dengan tajdid (pembaharuan) baik buku, e-book serta media elektronik. Dan yang menjadi fokus pada penelitian ini adalah bagaimana pemikiran tajdid Ibnu Abdul Wahhab dalam Kitab Al-Ushul Ats-Tsalatsah

\section{Genealogi Keilmuan Syaikh Muhammad bin Abdul Wahhab}

Nama lengkapnya adalah Muhammad bin Abdul Wahhab bin Sulaiman bin 'Ali bin Muhammad bin Rasyid bin Buraid bin Muhammad bin Musyrif bin Umar AtTamimy an-Najdy salah seorang keturunan Bany Tamim, ia juga sering disebut Syaikh Muhammad At-Tamimy (as-Sulaiman, 2012, p. 1).

Ia dilahirkan di 'Uyainah pada tahun 1115 H (1713 M) (as-Sidawi, 2010, p. 49) dan wafat pada tanggal 29 Syawal 1206 H (1793 M) (Jainuri, 2013, p. 131) dalam usia 92 tahun. Ia mampu menghafal Alquran sebelum usia sepuluh tahun, kemudian ia 
mempelajari ilmu fikih hingga mendalam. Ia membaca kitab-kitab tafsir dan hadits dan senantiasa terlihat menuntut ilmu baik siang maupun malam, serta menghafal berbagai matan-matan berbagai disiplin ilmu pengetahuan (as-Sulaiman, 2012).

Hidup di tengah-tengah keluarga besar ulama, serta kondisi ekonomi yang mendukung ditambah dengan kecerdasan dan pribadi yang kuat membuatnya dengan penuh keleluasaan mendalami ajaran Islam. Tidak cukup hanya di 'Uyainah, ia menuntut ilmu ke beberapa pusat ilmu pengetahuan saat itu seperti Basrah, Disa', Madinah al Munawwarah, serta ulama-ulama yang ada di Nejed (Jainuri, 2013).

Rangkaian rihlah ilmiah Ibnu Abdul Wahhab dimulai sejak tahun $1135 \mathrm{H}$ menuju Mekah dan Madinah, disana ia berguru kepada Syaikh Abdul bin Salim alBashori Oliver (2012) serta dua ulama terkenal Abdullah Ibn Saif (seorang ahli fikih) dan Muhammad Hayah as-Sindi (seorang ahli hadis) (Jainuri, 2013).

Abu Mujahid dan Haneef Oliver (2012) menyebutkan bahwa kota ketiga yang dikunjungi oleh Ibnu Abdul Wahhab adalah Basroh. Di sana aia belajar pada Syaikh Muhammad al-Majmu'i, selama di Basroh ia belajar nahwu dan fikih. Kemudian menuju Ahsa' dan belajar pada Syaikh Muhammad bin Fairuz Al-Kafif, dari gurunya ini ia dapat menyalin karya-karya Ibnu Taimiyah dan Ibnu Qoyyim. Ia juga sempat berdiskusi tentang tauhid dan aqidah dengan Syaikh Abdullah bin Muhammad bin Abdul Latif Asy-Syafi'i Al-Ahsa'i dan Syaikh Muhammad bin Afaliq.

Ibnu Abdul Wahhab Masih kembali ke Hijaz dan menetap di sana (Mekah dan Madinah). Selama di Hijaz ia belajar pada beberapa ulama seperti Syaikh Ismail bin Muhammad al-Ajluni, Syaikh Ali Effendi bin Shodiq ad-Daghistani, Syaikh Abdul Karum ad-Daghistani, Syaikh Muhammad al-Burhani dan Syaikh Utsman Ad-Dayyar Bakri (Oliver, 2012).

Ibnu Abdul Wahhab kemudian kembali ke Huroimala' untuk menghadiri majelis talaqqi ayahnya, Abdul Wahhab bin Sulaiman. selain ber-talaqqi Ibnu Abdul Wahhab menggunakan waktunya untuk berdakwah kepada masyarakat setempat kepada tauhid dan melarang praktek-praktek kesyirikan. Pada tahun $1153 \mathrm{H}$ ayahnya wafat dan ayahnya menarik kembali semua pandangannya yang bertentangan dengan anaknya Ibnu Abdul Wahhab (Oliver, 2012).

Pemikiran dan dakwah Ibnu Abdul Wahhab terdengar sampai ke 'Uyainah sebuah kota yang dipimpin oleh Utsman bin Mu'ammar. Pada tahun 1154 H Ibnu Abdul 
Wahhab pindah ke 'Uyainah karena Utsman bin Mu'ammar menerima dakwahnya dan menyambutnya dengan penuh kehormatan. Di 'Uyainah ia diangkat menjadi hakim. Selama di 'Uyainah ia menghilangkan sarana kesyirikan seperti pohon-pohon yang dikeramatkan, kuburan-kuburan yang dijadikan tempat ibadah dan kubah-kubah diatas kuburan. Namun dakwahnya tidak berlangsung lama, setelah mendapat tekanan dari penguasa Ahsa', Utsman bin Mu'ammar meminta Ibnu Abdul Wahhab meninggalkan 'Uyainah (Oliver, 2012).

Ibnu Abdul Wahhab kemudian menuju Dir'iyyah dan tinggal bersama muridnya Ahmad bin Suwailim. Kabar kedatangan Ibnu Abdul Wahhab didengar oleh Muhammad bin Su'ud (pemimpin Dir'iyyah). Setelah mengadakan pertemuan mereka membuat kesepakatan untuk saling membantu dan tidak saling menghianati satu sama lain $(1157 \mathrm{H})$. Sejak saat itu, ia melanjutkan dakwahnya dari Dir'iyyah dan mendapat dukungan serta bantuan dari keluarga Muhammad bin Su'ud (Oliver, 2012).

Menurut Abu Mujahid dan Haneef Oliver (2012) pada masa itu Dir'iyyah atau wilayah Nejed pada umumnya dipenuhi dengan praktek-praktek kesyirikan, banyak kubah dibangun diatas kuburan bahkan kuburan yang diyakini sebagai kuburan Zaid bin Khottob (di Jubailah (Wadi Hanifah)) dijadikan tempat ibadah dan dijadikan tempat mencari berkah dengan cara mengusap-usap kubah kuburan tersebut serta bernazar di sisi kuburan. Selain itu, ada pula pohon-pohon tua yang dianggap keramat diibadahi dan diambil berkah, banyak wanita mandul mengusap-usap pohon tersebut seraya meminta anak. Realita tersebut semakin diperparah dengan menjamurkan praktik-praktik sihir dimana-mana.

\section{Tajdid (Pembaharuan)}

Secara etimologi kata "tajdid" diambil dari bahasa arab dalam bentuk fi'il tsulatsi mazid yaitu "jaddada-yujaddidu-tajdiidan" yang artinya memperbaharui (Munawwir, 1984, p. 173). Prof. Haedar Nashir (2010, p. 295) bahwa tajdid (pembaharuan) memiliki dua arti yakni (a) pemurnian, yakni memelihara matan ajaran Islam yang berdasarkan dan bersumber pada Alquran dan as-Sunnah as-Shohihah, dan (b) peningkatan, pengembangan, modernisasi, dan yang semakna dengannya, yakni penafsiran, pengamalan dan perwujudan ajaran Islam dengan tetap berpegang teguh kepada Alquran dan as-Sunnah as-Shohihah. 
Seiring berkembangnya zaman dan semakin jauhnya umat ini dari generasigenerasi terbaik Islam (shahabat, tabi'in dan tabi' tabiin) terjadi banyak pergeseran nilai-nilai agama yang murni, Islam mulai bercampur dengan kesyirikan, bid'ah, tahayul dan khurafat terkhusu pada zaman pertengahan (Nasution, 2003, p. 199). Pemikiran umat Islam semakin berkurang dan statis karena anggapan pada saat itu pintu ijtihad sudah tertutup. Sehingga kaum muslimin jatuh pada kejumudan berfikir dan taklid. Realita seperti ini hampir terjadi di setiap kehidupan kaum muslimin dari berbagai kalangan.

Melihat kondisi ummat yang sedemikian jauh dari syari'at perlu adanya pembaharuan-pembaharuan dalam Islam, terutama dalam aspek aqidah, memberikan pemahaman kepada kaum muslimin akan pentingnya mengembalikan segala bentuk persoalan yang ada kepada Alquran dan As-Sunnah, menyebarluaskan dan memajukan Islam serta mengajak untuk tetap istiqomah di jalan kebenaran.

Dalam hal pembaharuan Nabi Shallallahu 'alaihi wa sallam pernah bersabda :

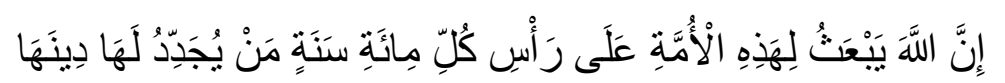

"Sesungguhnya pada setiap penghujung seratus tahun, Allâh Subhanahu wa Ta'ala akan mengutus untuk umat ini orang yang akan memperbaharui agama mereka."( HR Abu Daud no. 3740)

Benih pembaharuan dalam dunia Islam sesungguhnya telah muncul pada sekitar abad ke-XIII Masehi, suatu masa di mana pada saat itu umat Islam berada pada masa kemunduran dengan sangat drastis dalam berbagai bidang (Pasha, 2005, p. 28).

Pada tahun $1253 \mathrm{M}$, Hulagu Khan bergerak dari Mongol untuk membasmi kelompok Hasyasyin dan menyerang Daulah Abbasiyah. Pada Jamuari 1258, anak buah Hulagu Khan bergerak untuk meruntuhkan tembok ibukota. Pada 10 Februari, pasukannya telah merangsek ke dalam kota dan khalifah beserta tiga ratus pejabat serta qadhin buru-buru menawarkan penyerahan diri tanpa syarat. Sepuluh hari kemudian mereka dibunuh, kota dijarah dan dibakar, mayoritas penduduk dan keluarga kerajaan dibantai habis, dan untuk pertama kalinya dunia kaum muslimin tidak mempunyai seorang khalifah (Hitti, 2002, pp. 619-620).

Pasca jatuhnya kekhalifahan, dunia Islam mengalami kemunduran di berbagai sektor, kendati demikian masih terdapat kebangkitan pada masa tersebut yaitu pada fase 
1500-1700 (Daulah Utsmany di Turki, Safawy di Persia, dan Mughal di India). Namun pasca jatuhnya kekhilafahan Islam dan penjajahan asing kaum muslimin mengalami kejumudan dalam ilmu pengetahuan dan kemunduran dalam peradaban. Sejak saat inilah muncul berbagai tokoh pembaharu dalam dunia Islam (Nashir, 2010, p. 83).

Prof. Haedar Nashir (2010) mengatakan bahwa pelopor pembaharuan dalam dunia Islam adalah Ibnu Taimiyyah, Muhammad bin Abdul Wahhab, Jamaluddin alAfghani, Muhammad Abduh, Rasyid Ridla, Syaikh Waliyullah, Achmad Khan, dan sebagainya. Untuk kasus Indonesia diantara tokoh-tokoh yang dianggap sebagai pembaharu dalam Islam adalah Haji Rasul, Abdul Karim Amrullah, Djamil Djambek, sebelumnya para tokoh Paderi dengan gerakan pembaharuannya di ranah Minangkabau, termasuk Palimo Kayo yang mendirikan Sumatra Tawalib. Sedangkan di Pulau Jawa, pada era awal abad ke-XX, lahir Cokroaminoto yang mendirikan Syarikat Islam, KH. Ahmad Dahlan dengan Muhammadiyah, A.Hassan dengan Persatuan Islam, Achmad Surkati yang membentuk Al-Irsyad, dan lain-lain.

\section{Kitab Al-Ushul Ats-Tsalatsah}

Kitab ini berjudul Al-Ushul Ats-Tsalatsah atau Al-Ushul Ats-Tsalatsah wa Adillatuha. Penulisnya Muhammad bin Abdul Wahhab bin Sulaiman bin 'Ali bin Muhammad bin Rasyid bin Buraid bin Muhammad bin Musyrif bin Umar At-Tamimy. Kitab ini berisi pokok-pokok ajaran Islam yang wajib diketahui oleh setiap muslim. Dalam kitab ini setiap muslim wajib mengenal Allah, Dinul Islam, dan menganal Nabi Sallallahu 'Alai Wasallam, kemudian mengamalkan dan mendakwahkan ilmunya, serta bersabar terhadap berbagai gangguan yang muncul di dalamnya. Ilmu tentang Allah, Dinul Islam dan Nabi Muhammad Sallallahu 'Alaihi Wasallam adalah ilmu-ilmu pokok. Oleh kerena itu kitab ini dikenal dengan Kitab Al-Ushul Ats-Tsalatsah (Tiga Landasan Pokok / Tiga Prinsip Pokok).

Adapun isi kitab ini mencakup tiga pembahasan yaitu :

a. Muqoddimah

Muqoddimah berisi tiga pembahasan, pertama tentang wajibnya empat masalah (pertama, ilmu, yaitu ilmu mengenai Allah, mengetahui Nabi-Nya serta mengetahui agama Islam dengan dalil-dalil. kedua, mengamalkannya. Ketiga, Berdakwah kepadanya. keempat, bersabar dalam menghadapi gangguan di 
dalamnya). Kedua tentang wajibnya tiga perkara (pertama, bahwasanya Allah-lah yang menciptakan kita, Dialah yang memberi riski kepada kita dan tidak membiarkan kita terlantar, tetapi mengutus kepada kita seorang utusan. Kedua, bahwasanya Allah tidak ridha jika seorang menyekutukan-Nya dalam beribadah kepada-Nya, baik (menyekutukan-Nya) dengan malaikat yang dekat (dengan Allah) atau nabi yang diutus. Ketiga, Barangsiapa menaati Rasul dan mengesakan Allah, maka ia tidak boleh memberikan loyalitas kepada orang yang memusuhi Allah dan Rasul-Nya, meskipun kerabatnya yang paling dekat). Ketiga tentang penjelasan millah Ibrohim 'Alahi salam.

b. Inti Pembahasan

Kitab ini memuat tiga prinsip/landasan pokok yang wajib diketahui oleh setiap muslim yaitu, mengenal Allah (ma'rifatulloh), mengenal Dinul Islam dengan Dalil. mengenal Dinul Islam membagi kepada tiga tingkatan yaitu Iman, Islam dan Ihsan dan mengenal Nabi Sallallahu 'alahi Wasallam.

c. Penutup Kitab

Kitab ibi ditutup dengan pembahasan tentang hari akhir serta wajibnya seorang muslim mengingkari thoghut.

\section{Pemikiran Tajdid Syaikh Muhammad Bin Abdul Wahhab dalam Kitab Al-Ushul Ats-Tsalatsah}

Ensiklopedi Islam (1994, p. 156) menyebutkan bahwa Ibnu Abdul Wahhab membawa gerakan pembaharuan yang memiliki tujuan pemurnian terhadap perilaku keagamaan masyarakat Islam yang telah menyimpang dari ajaran yang sebenarnya. Timbulnya gerakan ini tidak bisa terlepas dari keadaan politik, ekonomi serta prilaku sosial keagamaan pada masa itu yang semakin melemah dan mengalami kemunduran. Pada umumnya di Semenanjung Arabia telah terjadi distorsi pemahaman Alquran serta menjamurnya sikap fatalis bahkan cenderung mistis.

Ibnu Abdul Wahhab berusaha untuk menurnikan agama Islam dari segala pemahaman dan praktek ibadah yang tidak sesuai dengan Alquran dan As-Sunnah. Kitab Al-Ushul Ats-Tsalatsah berisi beberapa pemikiran tajdid yang dilakukannya dalam berdakwah. Di antara tema yang menjadi titik tajdidnya adalah syirik, bid'ah dan tawasul. 


\section{a. Syirik}

Ensiklopedi Islam (1994, p. 16) menyebutkan bahwa syirik yang dimaksud adalah perbuatan, anggapan atau itikad menyekutukan Allah dengan yang lain. Seakan-akan ada yang maha kuasa di samping Allah. Menurut pengertian bahasa, berarti persekutuan atau bagian (nasib). Orang yang menyekutukan Allah disebut musyrik.

Ibnu Abdul Wahhab menolak perbuatan syirik termasuk di dalamnya sihir pada beberapa bagian dalam kitabnya, diantara perkataannya adalah sebagai berikut:

(Pertama) Bahwa Allah tidak ridha jika seorang menyekutukan-Nya dalam beribadah kepada-Nya, baik (menyekutukan-Nya) dengan malaikat yang dekat (dengan Allah) atau nabi yang diutus (At-Tamimy, 2013, p. 16).Maksudnya adalah bahwasanya Allah tidak ridha jika Allah disekutukan dengan yang lainnya dalam beribadah, ibadah adalah mutlak milik Allah dan Ia melarang manusia menyembah seseorang di samping menyembah Allah. Hal ini berdasarkan kepada firman Allah Tabaraka Wata'ala : Dan Sesungguhnya masjid-masjid itu adalah kepunyaan Allah. Maka janganlah kamu menyembah seseorangpun di dalamnya di samping (menyembah) Allah. (QS.Al-Jiin: 18). Sembahlah Allah dan janganlah kamu mempersekutukan-Nya dengan sesuatupun (QS. an-Nisa :36).

(Kedua)... yang paling agung Allah adalah perintah tauhid, yakni mengesakan Allah dengan ibadah. Dan yang paling besar yang Allah larang adalah syirik, yakni menyeru yang lain disamping menyembah Allah (At-Tamimy, 2013, p. 17). Maksud perintah tauhid adalah mengesakan Allah dalam hal rububiyah-Nya, uluhiyah-Nya, dan asma wa sifat-Nya. Dalam artian beribadah kepada Allah dengan penuh cinta, pengharapan dan pengagungan dan takut hanya kepada Allah semata. Sebaliknya syirik adalah larangan Allah yang sangat besar, karena syirik merupakan pembatal dan lawan dari tauhid, apabila perbuatan syirik tersebut dilakukan sampai ajal menjemput dan belum sempat bertaubat, maka Allah tidak akan mengampuninya serta mengaharamkan atasnya surga. Hal ini Allah kabarkan dalam firman-Nya : Sesungguhnya Allah tidak mengampuni dosa mempersekutukan (sesuatu) dengan Dia, dan Dia mengampuni dosa yang selain syirik bagi siapa yang dikehendaki-Nya. Barangsiapa yang mempersekutukan (sesuatu) dengan Allah, Maka Sesungguhnya ia telah tersesat sejauhjauhnya (QS. An-Nisa :116). Sesungguhnya orang yang mempersekutukan (sesuatu 
dengan) Allah, Maka pasti Allah mengharamkan kepadanya surga, dan tempatnya ialah neraka (QS. al-Maidah :72).

(Ketiga) Barangsiapa memalingkan sesuatu jenis ibadah tersebut kepada selain Allah, maka ia kafir lagi musyrik (At-Tamimy, 2013, p. 19). Jenis ibadah yang dimaksud disini adalah Iman, Islam dan Ihsan. Jadi dalam tiga aspek ibadah tersebut seorang muslim harus benar-benar bersih dari kesyirikan baik lahir maupun batinnya, dan barangsiapa memalingkan ibadah kepada selain Allah maka ia kafir dan musyrik. Sebagaimana firman Allah Tabaraka wa Ta'ala : Dan barangsiapa menyembah Tuhan yang lain di samping Allah, Padahal tidak ada suatu dalilpun baginya tentang itu, maka sesungguhnya perhitungannya di sisi Tuhannya. Sesungguhnya orang-orang yang kafir itu tiada beruntung (QS.al-Mu'minun :117).

(Keempat) Makna dari "Laa Ilaha Illallah" adalah tidak ada tuhan yang haq disembah melainkan Allah. Lafadz "Laa Ilaha” menafikan segala bentuk sesembahan selain Allah dan "Illallah" menetapkan bahwa segala bentuk ibadah hanya untuk Allah saja, yang tidak ada sekutu bagi-Nya dalam beribadah kepada-Nya dan tidak ada pula sekutu dalam kekuasaan-Nya (At-Tamimy, 2013, p. 19). Kalimat "Laa Ilaha Illallah" adalah kalimat syahadat tauhid mempunyai makna "Laa Ma'buda bi Haqqy Illah" (tidak ada yang diibadahi dengan haq kecuali Allah) melalui kalimat ini Allah mewajibkan kepada setiap muslim mengakui dalam lisan dan hatinya bahwasanya tidak ada sesembahan yang haq untuk diibadahi kecuali Allah. Kalimat "Laa Ilaha Illallah" mempunyai dua unsur, menafikan (meniadakan) berupa kalimat "Laa Ilaha” dan menetapkan dalam bentuk "Illallah" (as-Sulaiman, 2012, p. 124).

(Kelima) Allah mengutus seorang Rasul kepada setiap umat mulai Nabi Nuh sampai kepada Nabi Muhammad Sallallahu 'alai Wasallam mereka memerintahkan agar manusia menyembah Allah saja dan melarang mereka menyembah thaghut (AtTamimy, 2013, p. 27). Pernyataan Ibnu Abdul Wahhab disini mempunyai makna bahwa mentauhidkan Allah dan tidak mempersekutukaan-Nya dengan suatu apapun adalah merupakan inti dari dakwah para Rasul dari Nabi Nuh 'Alahi salam hingga Nabi Muhammad Sallallahu 'Alahi Wasallam. Hal ini senada dengan firman Allah Subhanahu Wata'ala : Sesungguhnya Kami mengutus kamu dengan membawa kebenaran sebagai pembawa berita gembira dan sebagai pemberi peringatan. dan tidak ada suatu umatpun melainkan telah ada padanya seorang pemberi peringatan (QS. Fathir 
:24). Dan sungguhnya Kami telah mengutus Rasul pada tiap-tiap umat (untuk menyerukan): "Sembahlah Allah (saja), dan jauhilah Thaghut itu (QS. an-Nahl : 36).

Ayat ini mafhum tentang perintah unutuk menjauhi thaghut, dan thaghut yang dimaksud pada masa Ibnu Abdul Wahhab adalah berhala-berhala berupa azimat, sihir, percaya kepada pohon yang mempunyai kekuatan, segala bentuk tahayul, khurafat dan sejenisnya, yang pada hakikatnya adalah tipu daya iblis (panglima thaghut) dalam menjemuskan manusia dalam kesyirikan. Ibnu Abdul Wahhab pun menyebutkan beberapa term yang masih memiliki kaitan dengan kesyirikan, diantaranya :

(Kelima) Barangsiapa menaati Rasul dan mengesakan Allah, maka ia tidak boleh memberikan loyalitas kepada orang yang memusuhi Allah dan Rasul-Nya, meskipun kerabatnya yang paling dekat (At-Tamimy, 2013, p. 16).

(Keenam) Islam adalah berserah diri (tunduk) kepada Allah dengan cara mentauhidkan, patuh kepada-Nya dengan ketaatan dan melepaskan diri dari kemusyrikan dan para pengikut syirik (At-Tamimy, 2013, p. 21).

(Ketujuh) Perbuatan menyembah berhala tinggalkanlah dan lepaskan dirimu darinya dan dari para penganutnya (At-Tamimy, 2013, pp. 24-25).

Pada initinya, pembaharuan yang dilakukan Ibnu Abdul Wahhab dalam memberantas kesyirikan adalah dengan mengembalikan segala bentuk aqidah atau kepercayaan masyarakat Islam yang telah ternodai oleh kesyirikan kepada Alquran dan As-Sunnah sebagaimana yang dipahami oleh generasi terdahulu (salaf) yang mana generasi ini Rasulullah sebutkan sebagai generasi terbaik umat Islam. Semangat pembaharuan yang dilakukan Ibnu Abdul Wahhab dalam memberantas kesyirikan mempunyai kesamaan dengan semangat pembaharuan yang dilakukan oleh Ibnu Taimiyah, yang mana Ibnu Taimiyah dijuluki sebagai "Imam Mujtahid Mutlaq " atau oleh Prof. H.A.R. Gibb disebut sebagai “...as profesor of Hambali Law” (Pasha, 2005, p. 30).

\section{b. Bid'ah}

Syeikh Sa'ad Yusuf Abu Aziz (2009, h. 29) menyebutkan bahwa bid'ah secara bahasa adalah sesuatu yang baru. Sedangkan menurut istilah syara' bid'ah adalah sebagaimana yang dikatakan oleh Imam Asy-Syatibi merupakan jalan agama yang 
dibuat-buat, yang menyerupai syariat, yang dilakukan dengan tujuan berlebih-lebihan dalam beribadah kepada Allah.

Pada masa hidup Ibnu Abdul Wahhab masyarakat Islam di Nejd dipenuhi dengan peribadatan-peribadatan bid'ah, diantaranya perayaan maulid Fatimah, maulid Khodijah, maulid Aminah, maulid Ali, hari raya 'Asyuro, melakukan peribadatan di kuburan, dan lain-lain. Tanggapan Ibnu Abdul Wahhab terhadap para pelaku bid'ah terdapat pada beberapa bagian dalam kitabnya, diantara perkataannya adalah sebagai berikut :

(Pertama) Imam Al-Bukhari rahimahullah mengatakan "Ilmu sebelum ucapan dan perbuatan (At-Tamimy, 2013, p. 15). Perkataan Iman Al Bukhori disini menunjukkan akan wajibnya seorang muslim mempunyai ilmu terlebih dahulu sebelum ucapan dan perbuatan, sedangkan ilmu yang dimaksud adalah apa yang diwahyukan oleh Allah berupa Alquran dan As-Sunnah sebagai uswah dari Nabi Muhammad Sallallahu 'Alahi Wasallam. Jadi ketika seorang muslim hendak berucap dan berbuat sesuatu yang diniatkan untuk ibadah kepada Allah maka ibadah tersebut harus sesuai dengan tuntunan yang ditetapkan oleh Alquan dan As-Sunnah, sedangkan perbuatan bid'ah adalah perbuatan yang dilakukan dengan niat ibadah namun tidak memiliki dalil yang terdapat pada Alquran maupun As-Sunnah. Allah Subhanahu Wata'ala berfirman : Maka ketahuilah, bahwa sesungguhnya tidak ada Ilah (sesembahan, Tuhan) selain Allah dan mohonlah ampunan bagi dosamu (QS. Muhammad : 19). Ayat ini menjadi dalil tentang wajibnya mengetahui ilmu sebelum ucapan dan perbuatan, karena dalam ayat ini Allah memulainya dengan kata "Fa'lam" (ketahuilah) yang merupakan perintah untuk mengetahui ilmu sebelum kata "Laa Ilaha Illallah" sebagai kalimat pengesaan kepada Allah.

(Kedua) Makna "Muhammad adalah Rasulullah" adalah menaatinya pada apa yang ia perintahkan, membenarkan apa yang dikabarkannya dan meninggalkan segala yang dilarangnya serta tidak beribadah kepada Allah melainkan dengan cara yang beliau syari'atkan (At-Tamimy, 2013, p. 22). Kalimat “Muhammad adalah Rasulullah" adalah kalimat syahadat rasul, yang mempunyai arti bahwa setiap muslim harus mengimani dalam hati dan mengakui dengan lisan bahwasanya Muhammad bin Abdillah adalah seorang Nabi dan Rasul Allah untuk seluruh alam semesta dari kalangan jin dan manusia. Kalimat "Muhammad adalah Rasulullah" mempunyai konsekuensi 
membenarkan segala sesuatu yang datangnya dari Nabi Sallallahu 'Alai Wasallam dalam bentuk menjalankan syariat Islam sesuai dengan yang diajarkan oleh Nabi Sallallahu 'Alai Wasallam.

(Ketiga) Agama Nabi Muhammad Sallallahu 'alai Wasallam kekal. Dan inilah agamanya itu, yang tidak ada suatu kebaikan pun melainkan telah ditunjukkan kepada umatnya, dan tidak pula keburukan melainkan mereka telah diperingatkan tentang bahayanya. Adapun kebaikan yang ditunjukan adalah tauhid serta segala yang dicintai dan dan diridhai Allah. Sedangkan keburukan yang diperingatkan bahayanya adalah syirik serta segala yang dibenci dan dimurkai oleh Allah untuk seluruh manusia. Allah juga mewajibkan kepada seluruh jin dan manusia untuk menaatinya (At-Tamimy, 2013).

Pada pernyataan di atas Ibnu Abdul Wahhab ingin menyampaikan bahwa syari'at Islam sudah sempurna dan tidak memerlukan tambahan lagi, kewajiban seorang muslim dalam hal beribadah kepada Allah hanyalah sami'na wa atho'na, dengan menjalankan segala bentuk ibadah sesuai dengan yang diajarkan Nabi Sallallahu 'Alai Wasallam dan tidak perlu dibumbui dengan unsur-unsur bid'ah, yang pada hakikatnya akan merusak syariat itu sendiri.

\section{c. Tawasshul}

Tawasshul mempunyai arti sebagaimana yang dikatakan Dr. Shalih bin Fauzan al-Fauzan (2012, h. 89) yaitu mendekatkan diri dan berupaya sampai kepada sesuatu, wasilah yaitu keadaan kedekatan, atau apa yang mendekatkan kepada orang lain. Jadi tawasshul adalah mengambil sarana agar doa dan ibadahnya diijabah oleh Allah Subhanahu wata'ala.

Di Jubailah (Wadi Hanifah) ada satu kuburan yang diyakini sebagai kuburan Zaid bin Khottob dijadikan tempat ibadah dan dijadikan tempat mencari berkah dengan cara mengusap-usap kubah kuburan tersebut serta ada sebagian orang yang bernazar di sisi kuburan. Kegiatan mengusap-usap kubah kuburan dengan maksud agar keinginannya dikabulkan oleh Allah dengan perantara penghuni kuburan tersebut adalah salah satu bentuk tawashul yang dilarang oleh agama.

Menanggapi hali ini Ibnu Abdul Wahhab membawakan dua dalil : 
Hanya Engkaulah yang kami sembah dan hanya kepada Engkaulah kami meminta pertolongan (QS. Al-Fatihah : 5).

Jika kamu memohon pertolongan, maka memohonlah kepada Allah".(HR. Imam Ahamad 1/293 dan at-Tirmidzi, 4/575).

Dalam Islam terdapat dua macam tawasshul, tawasshul yang dibolehkan dan tawasshul yang dilarang. Tawasshul yang dibolehkan adalah tawasshul dengan amal sholih, tawasshul dengan asmaul husna yang sesuai dengan hajatnya ketika berdoa, tawasshul dengan sifat-sifat Allah Tabaraka Wata'ala, tawasshul dengan meminta doa kepada orang sholih yang masih hidup, tawasshul dengan keimanannya kepada Allah Subhanahu Wata'ala dan tawasshul dengan ketauhidannya kepada Allah 'Azza Wajalla (Salam, 2011, pp. 134-138).

Adapun tawasshul yang dilarang dalam Islama adalah ; pertama, bertawasshul kepada orang yang sudah mati. Kedua, bertawasshul dengan cara menyebut nama atau kemuliaan orang shalih ketika berdoa kepada Allah Subhanahu wa Ta'ala. Ketiga, bertawasshul dengan cara beribadah kepada Allah Tabaraka wata'ala di sisi kubur orang sholih serta menyakini bahwa penghuni kubur punya andil, ini bisa menjadi perantara kesyirikan (Salam, 2011, pp. 134-138).

Syaikh Utsaimin (2012, h.102) mengatakan bahwa memohon pertolongan kepada orang mati secara mutlak atau kepada orang yang masih hidup dalam masalah yang ghaib, yang mana ia tidak mampu melakukannya. Hal ini jelas masuk dalam kategori perbuatan syirik.

Pada dasarnya inti ajaran yang dibawa oleh Ibnu Abdul Wahhab sangat dipengaruhi oleh ajaran yang dibawa Ibnu Taimiyah. Ada dua inti ajaran yang dibawa Ibnu Abdul Wahhab. Pertama, kembali kepada ajaran yang asli, yakni ajaran yang dibawa oleh dan dipraktekkan oleh Nabi Muhammad, para shahabat dan tabi'in. Kedua, prinsip yang berhubungan dengan masalah tauhid. Sejatinya pemikiran yang dicetuskan oleh Syaikh Muhammad bin Abdul Wahhab adalah bentuk reaksi terhadap suasana ketauhidan yang telah dirusak oleh faham musyrik, bukan merupakan gerakan politik.

Adapun strategi dakwah yang dilakukan Syaikh Muhammad bin Abdul Wahhab adalah sebagai berikut : pertama, seruan penegakan tauhidullah merupakan misi kerasulan dan bagian paling utama dalam dakwah serta sebagai bentuk perlawanan terhadap kemusyrikan, bid'ah dan khurafat. Kedua, menjalankan amar ma'ruf nahyi 
munkar dengan menegakkan hukum Allah dalam pidana, seperti hukum rajam dan jilid. Ketiga, menjauhkan umat dari kebodohan dan perpecahan serta ikhtilaf. Keempat, menyiapkan seorang pemimpin yang bisa mempersatukan kaum muslimin. Kelima, seruan jihad fii sabilillah ditegakkan melalui kekuasaan negara dengan merujuk kepada masa Rasulullah Sallallahu 'alai Wasallam. Keenam, menjadikan Nejd sebagai daerah pemerintahan dan dakwah di bawah bendera Laa Ilaha Illallah, Muhammad Rasulullah. Ketujuh, menjadikan Dir'iyyah sebagai pusat yang mengendalikan gerakan dakwah dan seruan untuk mengumandangkan jihad ke berbagai wilayah keamiran di sekitar Nejd. Selain tujuh strategi dakwah di atas, dilakukan pula pengembangan dakwah melalui karya tulis dan surat menyurat ke berbagai wilayah dunia, secara khusus ke wilayah Daulah Utsmaniyah (Jainuri, 2013).

Pemikiran Ibnu Abdul Wahhab sangat menentang keras kesyirikan serta wahana-wahana yang mengantarkan kepada kesyirikan, sehingga setelah ia bergabung dan bekerjasama dengan Muhammad bin Su'ud dan mendapat topangan kekuatan ia menghancurkan bangunan kuburan-kuburan yang dikeramatkan oleh sebagian kaum muslimin saat itu baik itu yang ada di Madinah, Nejd maupun yang ada di Najef (kuburan Ali r.a) dan di Karbala (kuburan Husain) yang dikeramatkan oleh kaum Syi'ah dan tak terkecuali membongkar kubah kuburan Nabi sallallahu alaihi wasalaam yang ada di Madinah. Tajdid yang dibawa oleh Ibnu Abdul Wahhab sangat ketat, segala bentuk penyimpangan yang akan dihilangkan. (Nashir, 2010).

Sejak bekerjasama dengan Muhammad bin Su'ud pemikiran tajdid Ibnu Abdul Wahhab meluas di seluruh Saudi Arabia bahkan hampir ke seluruh Jazirah Arab hingga ke seluruh negeri Islam negeri seperti India, Sudan, Libya dan Indonesia (Nashir, 2010).

\section{Penutup}

Pemikiran Ibnu Abdul Wahhab ini tidak bisa terlepas dari keadaan politik, ekonomi serta prilaku sosial keagamaan pada masa itu yang semakin melemah dan mengalami kemunduran. Menjamurnya praktek-praktek kesyirikan, tahayul, praktek sihir, bernazar dan beribadah di kuburan, meminta bantuan kepada pohon-pohon keramat dan orang yang telah wafat, percaya kepada azimat, penangkal penyakit dan lain-lain. Di tengah-tengah kehidupan yang sedemikian mundur Ibnu Abdul Wahhab menganngap perlu untuk melakukan tajdid (pembaharuan). Namun sejatinya benih 
tajdid dalam dunia Islam telah muncul pada sekitar abad ke-XIII Masehi. Syaikh Muhammad bin Abdul Wahhab memiliki tujuan pembaharuan, yakni menyeru kepada tauhid yang murni dan tidak bercampur dengan unsur kesyirikan serta berupaya mengembalikan tatacara beragama kepada yang sesuai dengan Alquran dan as-Sunnah dengan menghilangkan perkara-perkara yang sifatnya dapat merusak kemurnian agama. IbnuAbdul Wahhab menentang keras kesyirikan dan wahana-wahana yang mengantarkannya kepada jalan kesyirikan. Kitab Al-Ushul Ats-Tsalatsah menyinggung beberapa poin yang berkaitan langsung dengan kondisi sosial keagamaan masyarakat pada saat itu seperti bahaya syirik, thagut, bid'ah, tukang sihir dan lain-lain. Imam AlBukhari rahimahullah mengatakan "Ilmu sebelum perkataan dan perbuatan". Dalam kitab tersebut juga dijelaskan bahwa ada perbedaan pemahaman terkait konsep syirik, bid'ah dan tawashhul perspektif Ibnu Abdul Wahhab dan yang terjadi di kalangan masyarakat luas. Dalam Kitab Al-Ushul Ats-Tsalatsah Ibnu Abdul Wahhab menyebutkan ada tiga landasan utama yang harus dipahami oleh setiap muslim, yaitu mengenal Allah, mengenal Agama Islam dan mengenal Nabi Muhammad Sallallahu 'Alahi Wasallam.

Pemikiran tajdid Ibnu Abdul Wahhab sangat berdampak pada kondisi sosial keagamaan di wilayah Nejd dan Saudi Arabia pada umunya, terlebih lagi setelah mendapat topangan kekuatan dari Muhammad bin Su'ud ia melakukan pembaharuan ke wilayah lain yang dianggap melakukan penyimpangan dengan tegas. Pemikiran tajdid Ibnu Abdul Wahhab bukan hanya menyebar di wilayah Saudi Arabia dan sekitarnya saja, namun telah menyabar hampir ke seluruh negeri-negeri berbasis massa Islam yang ada di dunia bahkan di bumi nusantara hingga ini. Maka sangat mafhum jika ia dianggap sebagai salah satu tokoh mujaddid paling berpengaruh di abad ke-XX. Sebagai seorang mujaddid, Ibnu Abdul Wahhab menuai banyak respon dari kalangan intelektual baik muslim maupun non muslim, baik respo positif dengan menerima pemikirannya atau respon negatif dengan memberikan gelar wahabi, aliran sekte keras, fundamentalis, mujasimah, kaku yang dihawatirkan akan berdampak pada perpecahan dan permusuhan di kalangan kaum muslimin sendiri, khususnya di kalangan ahlussunnah wal jamaah. Oleh karena itu penulis berharap kepada kaum muslimin sekalian untuk bertindak lebih arif dan objektif dalam mensikapi pemikiran semacam ini, sehingga tidak terjadi kesalahfahaman di kalangan masyarakat muslim. Tulisan ini diharapkan bisa menjadi 
solusi titik temu di antara perbedaan persepsi dalam upaya menjaga kehormatan dan hubungan baik di kalangan ulama-ulama ahlus sunnah wal jama'ah. Wallahu a'alam wasallallahu 'ala Nabiyuina Muhammad Sallallahu 'alaihi wasallam.

\section{DAFTAR PUSTAKA}

al-Fauzan, F.(2012). Kitab At-Tauhid. Jakarta : Muassasah As-Shofwah Al-Islamiyyah. al-Utsaimin, S. (1421 H). Syarh ats-Tsalatsah al-Utsul. Kairo : Dar Ibnu al-Jauziyah as-Sidawi, A. U. (2010). Meluruskan Sejarah Wahabi. Gresik : Putaka Al-Furqan. as-Sulaiman, F. b. (2012). Syarah Al-Ushul Ats-Tsalatsah Ulasan Tuntas Tentang Tiga Prinsip Pokok Siapa Rabbmu, Apa Agamamu, Siapa Nabimu (diterjemahkan dari Syaikh Muhammad bin Shalih al-Utsaimin. Syarhu Tsalatsatul Utsul). Jakarta: Darul Haq.

At-Tamimy, I. M. (2013). Al-Ushul Ats-Tsalatsah, Jami' Al-Mutun Lil 'Ilmiyyah Fi Al'Ulumi Asy-Syar'iyyah. Kairo: Darul Al-'Alimiyyah Li Al-Naysri Wa At-Tauzi'. Ensiklopedi Islam. (1994). Jakarta : PT Ichtiar Baru Van Hoeve.

Gunawan, I. (2013). Hakikat Wahhabiyah dan Klaim Wahhabi. As-sunnah, 23.

Hitti, P. K. (2002). History Of The Arabs, New York : Palgrave Macmillan. terj. R. Cecep Lukman Yasin. Jakarta: PT Serambi Ilmu Semesta.

Jainuri, A. (2013). Muhammadiyah Dan Wahhabisme Mengurai Titik Temu Dan Titik Seteru. Yogyakarta: Suara Muhammadiyah.

Munawwir, A. (1984). Kamus Al-Munawwir Arab-Indonesia Terlengkap. Yogyakarta: Penerbit Pustaka Progresif.

Nashir, H. (2010). Muhammadiyah Gerakan Pembaruan. Yogyakarta: Suara Muhammadiyah.

Nasution, H. (2003). Pembaharuan dalam Islam Sejarah Pemikiran dan Gerakan. Jakarta: PT Bulan Bintang.

Oliver, A. M. (2012). Virus Wahabi Mitos Negatif Bagi Salafi. Bandung: Toobagus Publishing.

Pasha, M. K. (2005). Muhammadiyah Sebagai Gerrakan Islam. Yogyakarta: Pustaka SM.

Salam, A. I. (2011). Mutiara Faedah Kitab Tauhid. Yogyakarta: Pustaka Muslim.

Waskito, A. (2011). Bersikap Adil Kapada Wahabi Bantahan Kritis dan Fundamental Terhadap Buku Propaganda Karya Syaikh Idahram. Jakarta: Pustaka AlKautsar. 